\title{
Commentary: Tetralogy of Fallot under the microscope
}

\author{
Pierre-Luc Bernier, MD, CM, MPH, FRCSC
}

\footnotetext{
From the Division of Cardiovascular Surgery, Department of Pediatric Surgery, McGill University, Montreal, Quebec, Canada.

Disclosures: Author has nothing to disclose with regard to commercial support.

Received for publication May 1, 2019; accepted for publication May 3, 2019; available ahead of print June 18, 2019 .

Address for reprints: Pierre-Luc Bernier, MD, CM, MPH, FRCSC, The Montreal Children's Hospital, McGill University Health Center, 1001 Decarie Boulevard, Room B.04.2917, Montreal, Quebec H4A 3J1, Canada (E-mail: pierre-luc.bernier@mcgill.ca).

J Thorac Cardiovasc Surg 2019;158:1184

$0022-5223 / \$ 36.00$

Crown Copyright (C) 2019 Published by Elsevier Inc. on behalf of The American Association for Thoracic Surgery https://doi.org/10.1016/j.jtcvs.2019.05.013
}

Tetralogy of Fallot (TOF) occupies a central place in the history of the treatment of congenital heart disease. In 1944, it was the first lesion to be palliated, ${ }^{1}$ and in 1954 , it was the first lesion to be repaired. ${ }^{2}$ Since this time, our understanding of the pathophysiology of TOF has greatly evolved. The surgical methods used to correct this cyanotic lesion have progressed, leading to excellent short- and midterm outcomes, and in many cases, favorable long-term outcomes. However, it is becoming increasingly recognized that many patients remain hemodynamically compromised because of residual pulmonary lesions or myocardial issues. Therefore, much remains to be elucidated to guarantee our young patients with TOF become healthy teenagers and adults without having to endure the strains of frequent reinterventions. Central to this is the fact that the right ventricle of patients with TOF is constantly living under stress. Before initial repair, the stress is obstruction. After surgery, at times, the pulmonary regurgitant volume load is a source of stress. Later on, after pulmonary valve replacement and the inevitable structural valve degeneration, obstruction returns as a stressor. The cycle goes on. Our understanding of TOF still needs to be enriched. We need to allow these ventricles to live a restful existence. This may be achieved by better tailoring our tolerance for residual outflow obstruction and optimizing timing of the initial and subsequent interventions.

Looking at the myocytes for the answer may be a good starting point. The article by Chowdury and colleagues ${ }^{3}$ delves into some key issues related to TOF and proposes a unique and interesting method. The authors establish correlations between hemodynamic parameters derived from echocardiography measurements and histopathology findings in patients with repaired TOF. Here, the authors are interested in the stress sustained by the right ventricle before the initial repair. Two-dimensional and tissue Doppler imaging variables ascertaining the performance of the right ventricle are analyzed in parallel to histologic abnormalities such as myocardial hypertrophy, myocytolysis, and perivascular fibrosis. This cohort from the emerging world is composed mostly of nonpalliated patients who

\section{References} 142:418-45. 1173-83.e5.

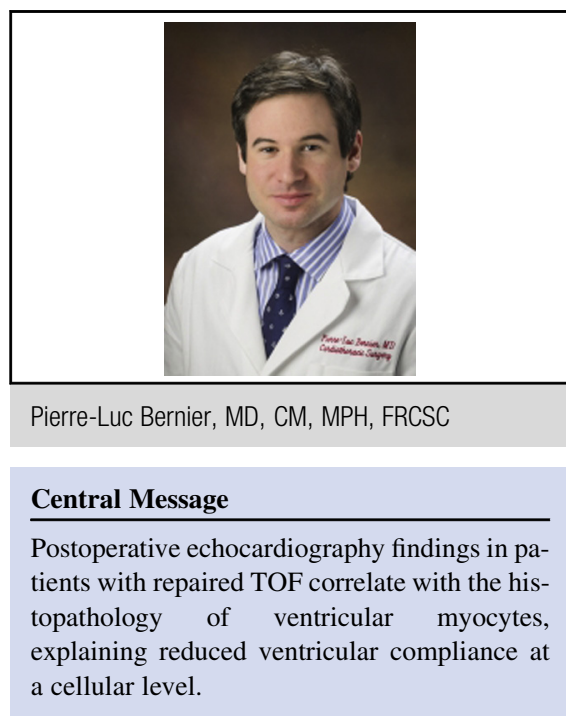

See Article page 1173 .

underwent late repair $(65 \%$ aged $>3$ years at operation; range, 18 months to 26 years at operation). Interestingly, but not surprisingly, only $11 \%$ of the patients studied demonstrate a normal myocardial histology of the right ventricle. Perivascular fibrosis is identified as a major predictor for absence of improvement in diastolic compliance of the right ventricle.

Some could argue that the cohort studied is not representative of the patients treated in the Western world. Although this may be true, the findings of Chowdury and colleagues ${ }^{3}$ make a strong argument for early corrective surgery. It is also an invitation to consider these histologic abnormalities and their clinical implications throughout the continuum of care of patients with TOF. To ensure that our patients with TOF grow to become healthy adults, the proper timing of the initial repair and subsequent valve implantation are critical to maintaining the health of the right ventricle.

1. Blalock A, Taussig HB. The surgical treatment of malformations of the heart in which there is pulmonary stenosis or pulmonary atresia. JAMA. 1945;128:189.

2. Lillehei CW, Cohen M, Warden HE, Read RC, Aust JB, Dewall RA, et al. Direct vision intracardial surgical correction of the tetralogy of Fallot, pentalogy of Fallot, and pulmonary atresia defects: report of the first ten cases. Ann Surg. 1955;

3. Chowdury UK, Jha A, Ray R, Kalaivani M, Hasija S, Kumari L, et al. Histopathology of the right ventricular outflow tract and the relation to hemodynamics in patients with repaired tetralogy of Fallot. J Thorac Cardiovasc Surg. 2019;158: 